\title{
Tea and coffee intake in relation to risk of breast cancer in the Black Women's Health Study
}

\author{
Deborah A. Boggs ${ }^{1}$, Julie R. Palmer ${ }^{1}$, Meir J. Stampfer ${ }^{2,3,5}$, Donna Spiegelman ${ }^{2,4}$, Lucile L. \\ Adams-Campbell ${ }^{6}$, and Lynn Rosenberg ${ }^{1}$ \\ ${ }^{1}$ Slone Epidemiology Center at Boston University, Boston, MA \\ ${ }^{2}$ Department of Epidemiology, Harvard School of Public Health, Boston, MA \\ ${ }^{3}$ Department of Nutrition, Harvard School of Public Health, Boston, MA \\ ${ }^{4}$ Department of Biostatistics, Harvard School of Public Health, Boston, MA \\ ${ }^{5}$ Channing Laboratory, Department of Medicine, Brigham and Women's Hospital and Harvard \\ Medical School, Boston, MA \\ ${ }^{6}$ Lombardi Comprehensive Cancer Center, Georgetown University, Washington, DC
}

\begin{abstract}
Prospective studies of tea and coffee intake and breast cancer risk have yielded inconsistent results. None of these studies has reported separately on African-American women. We prospectively examined the relation of tea and coffee consumption to risk of breast cancer among 52,062 women aged 21 to 69 at enrollment in 1995 in the Black Women's Health Study. Dietary intake was assessed in 1995 and 2001 using a validated food frequency questionnaire. Cox proportional hazards models were used to estimate incidence rate ratios (IRR) and $95 \%$ confidence intervals (CI), adjusted for breast cancer risk factors. During 12 years of follow-up through 2007, there were 1,268 incident cases of breast cancer. Intakes of tea, coffee, and caffeine were not associated with risk of breast cancer overall. The IRRs for consumption of $\geq 4$ cups/day compared with none were 1.13 (95\% CI 0.78-1.63) for tea and 1.03 (95\% CI 0.77-1.39) for coffee, and the IRR for the top quintile relative to the bottom quintile of caffeine intake was 1.04 (95\% CI 0.871.24). Consumption of tea, coffee, and caffeine was not associated with breast cancer risk according to menopausal status or hormone receptor status. Our findings suggest that intakes of tea, coffee, and caffeine are not associated with risk of breast cancer among African-American women.
\end{abstract}

\section{Keywords}

tea; coffee; caffeine; breast cancer; African Americans

\section{INTRODUCTION}

Tea and coffee are sources of flavonoids, lignans, and other polyphenols, ${ }^{1,2}$ which experimental evidence has shown may act as antioxidants, inhibit tumor cell proliferation, and decrease aromatase activity. ${ }^{3}$ Coffee and tea are also major sources of caffeine, which may affect estrogen metabolism, although evidence is inconsistent. ${ }^{4-7}$ Two studies reported

Correspondence to: Deborah A. Boggs, Slone Epidemiology Center at Boston University, 1010 Commonwealth Avenue, Boston, MA 02215, Tel: 617-734-6006; Fax: 617-738-5119; dboggs@ bu.edu. 
that higher caffeine or coffee intake was associated with lower estradiol levels, ${ }^{4,5}$ whereas other studies observed a positive ${ }^{6}$ or no association. ${ }^{7}$

A meta-analysis reported an inverse association between green tea intake and breast cancer risk, but the results for black tea, the type of tea most commonly consumed in Western populations, were conflicting; an inverse association between black tea and breast cancer was observed among eight case-control studies, whereas among five cohort studies there was a modest significant increase in risk of breast cancer. ${ }^{8}$ Since the publication of the meta-analysis, a prospective study also reported a significant positive association between black tea intake and risk of breast cancer, ${ }^{9}$ whereas two others observed no association. ${ }^{10,11}$

A meta-analysis of coffee consumption observed no overall association among nine cohort studies. ${ }^{12}$ Recent prospective studies have also reported no association between intakes of coffee and caffeine and overall risk of breast cancer, ${ }^{9,10}$ but there is some evidence that coffee and caffeine intake may be inversely associated with postmenopausal breast cancer. ${ }^{11}$

The distribution of breast cancer incidence differs between white and black women, with African-American women being more likely to be diagnosed with hormone receptornegative tumors. ${ }^{13}$ Dietary habits differ as well, with African-American women drinking less tea and coffee than white women. ${ }^{14}$ No epidemiologic studies have assessed breast cancer risk in relation to tea and coffee intake among African-American women. In a large cohort of African-American women, we prospectively investigated the association between intakes of tea, caffeinated and decaffeinated coffee, and caffeine and risk of breast cancer overall and according to menopausal status and estrogen receptor (ER) and progesterone receptor $(\mathrm{PR})$ status.

\section{MATERIALS AND METHODS}

\section{Study population}

The Black Women's Health Study (BWHS) is an ongoing prospective follow-up study of black women in the U.S. The study was established in 1995 when women from all regions of the U.S. were enrolled through postal questionnaires. ${ }^{15}$ The baseline questionnaire collected information on demographic characteristics, lifestyle factors, and medical history, and usual diet was assessed through a food frequency questionnaire (FFQ). A total of 59,000 women aged 21 to 69 years whose addresses were judged to be valid have been followed through mailed questionnaires every two years. Follow-up questionnaires update exposure information and identify incident cancers and other illnesses. Follow-up has averaged over $80 \%$ of the baseline cohort over six questionnaire cycles. We excluded women with a history of breast cancer $(\mathrm{N}=732)$ or other cancer except nonmelanoma skin cancer $(\mathrm{N}=743)$ at baseline, as well as participants who had left more than $10 \mathrm{FFQ}$ items blank $(\mathrm{N}=1,954)$ or had missing or implausible energy intake values $(<500$ or $>3800 \mathrm{kcal})(\mathrm{N}=3,536)$. After these exclusions, 52,062 women remained in the present analysis.

\section{Assessment of breast cancer}

Incident cases of breast cancer were ascertained through self-report on biennial follow-up questionnaires between 1995 and 2007. We asked all women who reported incident breast cancer for written permission to review their medical records. We obtained medical record or cancer registry data for $85 \%$ of cases, and of these, $99 \%$ were confirmed. We excluded disconfirmed cases. We obtained death certificate data for deaths reported by family members or the U.S. Postal Service. In addition, we searched the National Death Index for all nonrespondents and obtained death certificate data for all matches. Information on ER and PR status was obtained through abstraction of medical records and cancer registry data, and was available for $59 \%$ of cases. 


\section{Dietary assessment}

We assessed usual diet at baseline in 1995 with a 68 -item modified version of the National Cancer Institute-Block FFQ, and in 2001 with an 85 -item version. ${ }^{16}$ The nine frequency responses ranged from never or $<1$ serving/month to $\geq 2 /$ day for foods and to $\geq 6 /$ day for beverages. In 1995, we asked participants to specify a small, medium, or large portion size. A medium portion size was defined for each item (e.g. $1 / 2$ cup of broccoli), and small and large servings were weighted as 0.5 and 1.5 times a medium serving size, respectively. In 2001, a super-size portion, equivalent to 2 or more times the size of medium, was added. Caffeine intake was estimated by summing the caffeine content from coffee, tea, soft drinks, and chocolate candy. We assumed the caffeine content to be $137 \mathrm{mg}$ per cup of coffee, 47 $\mathrm{mg}$ per cup of tea, $46 \mathrm{mg}$ per can of cola, and $7 \mathrm{mg}$ per serving of chocolate candy. ${ }^{17}$ The FFQ item for soft drinks did not differentiate between caffeinated and decaffeinated soft drinks. Data from the Continuing Survey of Food Intakes by Individuals 1994-1996 indicate that caffeinated soft drinks comprise $75 \%$ of soft drink intake among African-American women, ${ }^{18}$ and therefore we weighted the caffeine content from soft drink intake reported on our FFQ by 0.75 . We adjusted caffeine for total energy intake using the nutrient residual method. ${ }^{19}$ The FFQ was validated among 408 participants using a three-day dietary record and up to three telephone 24-hour recalls. ${ }^{20}$ Energy-adjusted and deattenuated Pearson correlation coefficients for the FFQ compared with diet records and recalls ranged from 0.5 to 0.8 for total fat, saturated fat, protein, carbohydrate, fiber, calcium, vitamin $\mathrm{C}$, folate, and $\beta$-carotene.

\section{Assessment of nondietary exposures}

Information on education, age at menarche, weight at age 18 , and height was obtained at baseline in 1995. Data on current weight, vigorous physical activity, smoking status, alcohol intake, parity, age at first birth, oral contraceptive use, menopausal status, age at menopause, and menopausal hormone use were obtained at baseline and have been updated on biennial follow-up questionnaires. Body mass index (BMI) was calculated as weight in kilograms divided by squared height in meters. First-degree family history of breast cancer was ascertained on the 1995 and 1999 questionnaires. Women who reported a hysterectomy but retained one or both ovaries were classified as premenopausal if their current age was less than the $10^{\text {th }}$ percentile of age at natural menopause in the BWHS (43 years), as postmenopausal if their age was greater than the $90^{\text {th }}$ percentile of age at natural menopause in the cohort (56 years), and as uncertain menopausal status between the ages of 43 to 56 years.

\section{Statistical analysis}

Participants contributed person-years from the beginning of follow-up on March 1, 1995, to the diagnosis of breast cancer, death, loss to follow-up, or end of follow-up on March 1, 2007, whichever occurred first. Cox proportional hazards models, jointly stratified by age in one-year intervals and by questionnaire cycle, were used to estimate incidence rate ratios (IRR) and 95\% confidence intervals (CI) for risk of breast cancer in relation to intakes of tea, coffee, decaffeinated coffee, and caffeine. To reduce within-person variation and better represent long-term intake, we assessed cumulative average intake. ${ }^{21}$ Consumption at baseline was assessed in relation to breast cancer incidence between 1995 and 2001, and the average of 1995 and 2001 consumption was assessed in relation to breast cancer incidence between 2001 and 2007.

Multivariable models were adjusted for energy intake (quintiles), age at menarche $(<12,12$ $13, \geq 14$ years $)$, BMI at age $18\left(<20,20-24, \geq 25 \mathrm{~kg} / \mathrm{m}^{2}\right)$, family history of breast cancer (mother or sister), education ( $\leq 12,13-15, \geq 16$ years), geographic region (Northeast, South, Midwest, West), parity ( $0,1,2, \geq 3$ births), age at first birth ( $<20,20-24, \geq 25$ years), oral 
contraceptive use (never, use in last 5 years, use $\geq 5$ years ago), menopausal status (postmenopausal, premenopausal, uncertain), age at menopause ( $<45,45-49, \geq 50$ years), menopausal hormone use (never, ever use $<5$ years duration, $\geq 5$ years duration), vigorous activity (none, 1-4, $\geq 5$ hours/week), smoking status (never, past, current), and alcohol intake (none, 1-3, 4-6, $\geq 7$ drinks/week). Time-varying covariates were updated at the start of each questionnaire cycle. Tea, caffeinated coffee, and decaffeinated coffee were mutually adjusted for each other in the multivariable models.

Tests for trend were conducted using the median of each category modeled as a continuous variable. We assessed whether the association between tea, coffee, or caffeine intake and breast cancer risk was modified by menopausal status, age, BMI, or smoking status. Tests for interaction were performed using a likelihood ratio test that compared models with and without interaction terms.

\section{RESULTS}

Among 52,062 women at baseline, 22\% rarely or never drank tea and 19\% drank $\geq 1$ cup/ day, whereas $53 \%$ of women rarely or never drank coffee and $22 \%$ drank $\geq 1$ cup/day. Among regular coffee drinkers of at least 1 cup per day, median caffeine intake was $312 \mathrm{mg}$ / day, whereas among women who drank less than 1 cup of coffee per day, median caffeine intake was $41 \mathrm{mg} / \mathrm{day}$. The average contribution of coffee, tea, soft drinks, and chocolate candy to total caffeine intake was $87 \%, 7 \%, 5 \%$, and $1 \%$, respectively, among regular coffee drinkers, and $18 \%, 42 \%, 32 \%$, and $8 \%$, respectively, among non-regular coffee drinkers.

Table 1 presents the baseline characteristics of study participants according to tea and coffee intake. Both tea and coffee intake differed by geographic region across the U.S. Tea consumption was more common in the Northeast and less so in the Midwest or West, whereas coffee consumption was more common in the West and less in the South. Women who consumed more tea were also more likely to have completed college and be nulliparous. Women who consumed more coffee were more likely to be older, currently smoke, and drink more alcohol. Frequent tea consumption was associated with a prudent dietary pattern, whereas coffee consumption was unrelated to dietary pattern.

During 555,852 person-years of follow-up, we identified 1,268 cases of breast cancer; 562 cases $(44 \%)$ were premenopausal, $570(45 \%)$ were postmenopausal, and $136(11 \%)$ had uncertain menopausal status. Among 745 cases with known hormone receptor status, 366 (49\%) were ER+/PR+, 103 (14\%) were ER+/PR-, 12 (2\%) were ER-/PR+, and $264(35 \%)$ had ER-/PR - tumors. Cases with known and unknown hormone receptor status were similar with respect to tea and coffee consumption, age, education, and other lifestyle and reproductive factors.

Intakes of tea, coffee, decaffeinated coffee, and caffeine were not associated with overall risk of breast cancer (Table 2). The multivariable IRRs for $\geq 4$ cups/day of tea and coffee relative to no intake were 1.13 (95\% CI 0.78-1.63) and 1.03 (95\% CI 0.77-1.39), respectively. The IRR for $\geq 2$ cups/day of decaffeinated coffee compared with none was 0.82 (95\% CI 0.61-1.11). The IRR comparing the top to the bottom quintiles of caffeine was 1.04 (95\% CI 0.87-1.24).

Tea, coffee, and caffeine consumption was not associated with breast cancer risk according to menopausal status (Table 3). Among premenopausal women, the multivariable IRRs for $\geq 4$ cups/day of tea and coffee relative to no intake were 0.90 (95\% CI 0.48-1.69) and 1.33 (95\% CI 0.83-2.11), respectively, whereas the IRR for $\geq 2$ cups/day of decaffeinated coffee compared with none was 0.99 (95\% CI 0.56-1.72). Among postmenopausal women, the corresponding IRRs were 1.44 (95\% CI 0.89-2.34), 0.85 (95\% CI 0.55-1.32), and 0.93 
(95\% CI 0.65-1.33) for tea, coffee, and decaffeinated coffee, respectively. The multivariable IRRs comparing the top and bottom quintiles of caffeine were 0.97 (95\% CI 0.74-1.26) among premenopausal women and 1.03 (95\% CI 0.79-1.34) and postmenopausal women.

When we examined the associations jointly by menopausal status and ER/PR status, results by menopausal status did not appear to differ for ER+/PR+ and ER-/PR- breast cancer (Table 4). Results are not presented for $\mathrm{ER}+/ \mathrm{PR}-$ or $\mathrm{ER}-/ \mathrm{PR}+$ breast cancer because the number of cases was too small for meaningful interpretations.

\section{DISCUSSION}

In this large prospective study of African-American women, intakes of tea, coffee, and caffeine were not associated with overall risk of breast cancer. There were no significant associations within categories of menopausal status or hormone receptor status.

Epidemiologic studies of tea intake in relation to breast cancer risk have been inconsistent. A meta-analysis reported an inverse association between black tea and breast cancer incidence among eight case-control studies, but five cohort studies of predominantly postmenopausal women suggested a modest increase in breast cancer risk, with a summary OR of 1.15 (95\% CI 1.02-1.31) for highest vs. lowest intake. ${ }^{8}$ A more recent analysis from the Swedish Mammography Cohort observed a significant positive association between tea and breast cancer (IRR $=1.22,95 \%$ CI 1.05-1.42, for $\geq 2$ cups/day compared with none), and the association was stronger for ER+/PR+ breast cancer. ${ }^{9}$ No association between tea and risk of breast cancer was observed in the Nurses' Health Study ${ }^{11}$ or in the Women's Health Study. ${ }^{10}$ Although there was no association with breast cancer overall or with ER+/PR+ breast cancer in our study, there was a nonsignificant positive association of heavy tea consumption with postmenopausal breast cancer (IRR $=1.44$, 95\% CI $0.89-2.34$, for $\geq 4$ cups/ day compared with none). Relatively few women frequently drank tea, and power was therefore limited for detecting a modest association.

The mechanism by which tea could affect breast cancer risk is unclear. A study of postmenopausal Chinese women in Singapore reported lower plasma estrone and estradiol levels in green tea drinkers but higher levels in black tea drinkers than in non-tea drinkers. ${ }^{22}$ An in vitro study demonstrated that tea catechins exhibited antiestrogenic effects at high concentrations but estrogenic activity at lower concentrations. ${ }^{23}$ Green tea contains much higher concentrations of catechins than black tea, ${ }^{24}$ and these data support findings from previous studies that observed a protective effect of green tea, but not black tea, on breast cancer risk. ${ }^{8,25}$ Tea intake was positively associated with prolactin levels in a study among postmenopausal women in the Rotterdam Study, ${ }^{26}$ and the authors speculated that estrogenic effects of black tea may account for some of the protective association between tea intake and risk of coronary heart disease. However, no association between tea intake and circulating sex hormones was observed among postmenopausal women in the Nurses' Health Study. ${ }^{5}$

Epidemiologic studies of the relation between coffee and caffeine intake and breast cancer risk have also been inconsistent. A meta-analysis that included nine cohort studies reported no overall association between coffee consumption and risk of breast cancer. ${ }^{12}$ In the Nurses' Health Study, among postmenopausal women, there was a significant inverse association with caffeine intake (IRR $=0.88,95 \%$ CI $0.79-0.97$, for the highest vs. lowest quintile) and a borderline significant inverse association with coffee (IRR $=0.89,95 \% \mathrm{CI}$ $0.79-1.02$, for $\geq 4$ cups/day relative to none). ${ }^{11}$ Among postmenopausal women in our study, we observed a similar magnitude of association for coffee that was not significant (IRR $=0.85,95 \%$ CI $0.55-1.32$, for $\geq 4$ cups/day relative to none), but there was no 
association between caffeine intake and breast cancer. Half of the women in our cohort rarely drank coffee, and their levels of caffeine consumption are lower than that reported in studies comprised mostly of white women, ${ }^{10,11}$ among whom coffee and caffeine intake would tend to be more highly correlated than among African-American women.

Studies have shown that intakes of coffee and caffeine were positively associated with sexhormone binding globulin in postmenopausal women, 5,7 which could explain one mechanism for an inverse association between coffee intake and risk of breast cancer. ${ }^{27}$ Studies examining the association between coffee, caffeine, and circulating estrogens among premenopausal women have been conflicting. A study of older premenopausal women reported that caffeine was inversely associated with free estradiol, ${ }^{4}$ and the Nurses' Health Study reported lower luteal levels of total and free estradiol with increasing coffee consumption. ${ }^{5}$ However, one study observed that increasing coffee intake was associated with higher early follicular phase estradiol. ${ }^{6}$ A study of premenopausal, nulliparous women reported that coffee intake was positively associated with the ratio of 2-hydroxyestrone (2OHE1) to $16 \alpha$-hydroxyestrone (16 $\alpha$-OHE1) plasma levels. ${ }^{28}$ Evidence suggests that 2OHE1 has lower estrogenic activity than $16 \alpha-\mathrm{OHE} 1$, and that a high $2-\mathrm{OHE} 1 / 16 \alpha-\mathrm{OHE} 1$ ratio may be associated with a reduced risk of breast cancer. ${ }^{29-31}$ However, a study in a multiethnic population of premenopausal women observed higher urinary levels of both 2OHE1 and 16 $\alpha$-OHE1 with increasing caffeine consumption. ${ }^{32}$ Coffee has also been shown to be an important source of lignans in Western populations, ${ }^{33}$ and there is increasing evidence that high lignan intake is associated with a reduced risk of breast cancer. ${ }^{34}$

Strengths of our study include its large size, prospective design, high rate and length of follow-up, information on breast cancer risk factors and other potential confounders, and focus on African-American women. Misclassification of long-term tea and coffee intake would likely be random and would have attenuated true associations. It is possible that unknown lifestyle factors may have influenced our findings, but we were able to control for several established breast cancer risk factors, which did not appreciably affect our results.

In conclusion, our results suggest that tea, coffee, and caffeine consumption is not associated with risk of breast cancer among African-American women.

\section{Acknowledgments}

This work was supported by the National Cancer Institute (grant CA58420).

This work was supported by the National Cancer Institute (grant CA58420). We acknowledge the dedication of the Black Women's Health Study participants and staff.

\section{Abbreviations used}

$\begin{array}{ll}\text { IRR } & \text { incidence rate ratio } \\ \text { CI } & \text { confidence interval } \\ \text { ER } & \text { estrogen receptor } \\ \text { PR } & \text { progesterone receptor } \\ \text { FFQ } & \text { food frequency questionnaire } \\ \text { BMI } & \text { body mass index }\end{array}$




\section{References}

1. Chun OK, Chung SJ, Song WO. Estimated dietary flavonoid intake and major food sources of U.S. adults. J Nutr. 2007; 137:1244-52. [PubMed: 17449588]

2. Mazur WM, Wahala K, Rasku S, Salakka A, Hase T, Adlercreutz H. Lignan and isoflavonoid concentrations in tea and coffee. Br J Nutr. 1998; 79:37-45. [PubMed: 9505801]

3. Le Marchand L. Cancer preventive effects of flavonoids--a review. Biomed Pharmacother. 2002; 56:296-301. [PubMed: 12224601]

4. London S, Willett W, Longcope C, McKinlay S. Alcohol and other dietary factors in relation to serum hormone concentrations in women at climacteric. Am J Clin Nutr. 1991; 53:166-71. [PubMed: 1845789]

5. Kotsopoulos J, Eliassen AH, Missmer SA, Hankinson SE, Tworoger SS. Relationship between caffeine intake and plasma sex hormone concentrations in premenopausal and postmenopausal women. Cancer. 2009; 115:2765-74. [PubMed: 19384973]

6. Lucero J, Harlow BL, Barbieri RL, Sluss P, Cramer DW. Early follicular phase hormone levels in relation to patterns of alcohol, tobacco, and coffee use. Fertil Steril. 2001; 76:723-9. [PubMed: 11591405]

7. Ferrini RL, Barrett-Connor E. Caffeine intake and endogenous sex steroid levels in postmenopausal women. The Rancho Bernardo Study. Am J Epidemiol. 1996; 144:642-4. [PubMed: 8823059]

8. Sun CL, Yuan JM, Koh WP, Yu MC. Green tea, black tea and breast cancer risk: a meta-analysis of epidemiological studies. Carcinogenesis. 2006; 27:1310-5. [PubMed: 16311246]

9. Larsson SC, Bergkvist L, Wolk A. Coffee and black tea consumption and risk of breast cancer by estrogen and progesterone receptor status in a Swedish cohort. Cancer Causes Control. 2009

10. Ishitani K, Lin J, Manson JE, Buring JE, Zhang SM. Caffeine consumption and the risk of breast cancer in a large prospective cohort of women. Arch Intern Med. 2008; 168:2022-31. [PubMed: 18852405]

11. Ganmaa D, Willett WC, Li TY, Feskanich D, van Dam RM, Lopez-Garcia E, Hunter DJ, Holmes MD. Coffee, tea, caffeine and risk of breast cancer: A 22-year follow-up. Int J Cancer. 2008; 122:2071-6. [PubMed: 18183588]

12. Tang N, Zhou B, Wang B, Yu R. Coffee consumption and risk of breast cancer: a metaanalysis. Am J Obstet Gynecol. 2009; 200:290 e1-9. [PubMed: 19114275]

13. Carey LA, Perou CM, Livasy CA, Dressler LG, Cowan D, Conway K, Karaca G, Troester MA, Tse CK, Edmiston S, Deming SL, Geradts J, et al. Race, breast cancer subtypes, and survival in the Carolina Breast Cancer Study. JAMA. 2006; 295:2492-502. [PubMed: 16757721]

14. Storey ML, Forshee RA, Anderson PA. Beverage consumption in the US population. J Am Diet Assoc. 2006; 106:1992-2000. [PubMed: 17126630]

15. Rosenberg L, Adams-Campbell L, Palmer JR. The Black Women's Health Study: a follow-up study for causes and preventions of illness. J Am Med Womens Assoc. 1995; 50:56-8. [PubMed: 7722208]

16. Block G, Hartman AM, Naughton D. A reduced dietary questionnaire: development and validation. Epidemiology. 1990; 1:58-64. [PubMed: 2081241]

17. Willett WC, Stampfer MJ, Manson JE, Colditz GA, Rosner BA, Speizer FE, Hennekens CH. Coffee consumption and coronary heart disease in women. A ten-year follow-up. JAMA. 1996; 275:458-62. [PubMed: 8627967]

18. Agricultural Research Service. 1994-96, 1998 Continuing Survey of Food Intakes by Individuals (CSFII). US Department of Agriculture; 2000.

19. Willett W, Stampfer MJ. Total energy intake: implications for epidemiologic analyses. Am J Epidemiol. 1986; 124:17-27. [PubMed: 3521261]

20. Kumanyika SK, Mauger D, Mitchell DC, Phillips B, Smiciklas-Wright H, Palmer JR. Relative validity of food frequency questionnaire nutrient estimates in the Black Women's Health Study. Ann Epidemiol. 2003; 13:111-8. [PubMed: 12559670]

21. Hu FB, Stampfer MJ, Rimm E, Ascherio A, Rosner BA, Spiegelman D, Willett WC. Dietary fat and coronary heart disease: a comparison of approaches for adjusting for total energy intake and

Cancer Causes Control. Author manuscript; available in PMC 2011 November 1. 
modeling repeated dietary measurements. Am J Epidemiol. 1999; 149:531-40. [PubMed: 10084242]

22. Wu AH, Arakawa K, Stanczyk FZ, Van Den Berg D, Koh WP, Yu MC. Tea and circulating estrogen levels in postmenopausal Chinese women in Singapore. Carcinogenesis. 2005; 26:97680. [PubMed: 15661801]

23. Kuruto-Niwa R, Inoue S, Ogawa S, Muramatsu M, Nozawa R. Effects of tea catechins on the ERE-regulated estrogenic activity. J Agric Food Chem. 2000; 48:6355-61. [PubMed: 11312808]

24. Wang Y, Ho CT. Polyphenolic chemistry of tea and coffee: a century of progress. J Agric Food Chem. 2009; 57:8109-14. [PubMed: 19719133]

25. Wu AH, Yu MC, Tseng CC, Hankin J, Pike MC. Green tea and risk of breast cancer in Asian Americans. Int J Cancer. 2003; 106:574-9. [PubMed: 12845655]

26. Geleijnse JM, Witteman JC, Launer LJ, Lamberts SW, Pols HA. Tea and coronary heart disease: protection through estrogen-like activity? Arch Intern Med. 2000; 160:3328-9. [PubMed: 11088099]

27. Kaaks R, Rinaldi S, Key TJ, Berrino F, Peeters PH, Biessy C, Dossus L, Lukanova A, Bingham S, Khaw KT, Allen NE, Bueno-de-Mesquita HB, et al. Postmenopausal serum androgens, oestrogens and breast cancer risk: the European prospective investigation into cancer and nutrition. Endocr Relat Cancer. 2005; 12:1071-82. [PubMed: 16322344]

28. Jernstrom H, Klug TL, Sepkovic DW, Bradlow HL, Narod SA. Predictors of the plasma ratio of 2hydroxyestrone to 16alpha-hydroxyestrone among pre-menopausal, nulliparous women from four ethnic groups. Carcinogenesis. 2003; 24:991-1005. [PubMed: 12771045]

29. Kabat GC, O’Leary ES, Gammon MD, Sepkovic DW, Teitelbaum SL, Britton JA, Terry MB, Neugut AI, Bradlow HL. Estrogen metabolism and breast cancer. Epidemiology. 2006; 17:80-8. [PubMed: 16357599]

30. Fowke JH, Qi D, Bradlow HL, Shu XO, Gao YT, Cheng JR, Jin F, Zheng W. Urinary estrogen metabolites and breast cancer: differential pattern of risk found with pre- versus post-treatment collection. Steroids. 2003; 68:65-72. [PubMed: 12475724]

31. Muti P, Bradlow HL, Micheli A, Krogh V, Freudenheim JL, Schunemann HJ, Stanulla M, Yang J, Sepkovic DW, Trevisan M, Berrino F. Estrogen metabolism and risk of breast cancer: a prospective study of the 2:16alpha-hydroxyestrone ratio in premenopausal and postmenopausal women. Epidemiology. 2000; 11:635-40. [PubMed: 11055622]

32. Sowers MR, Crawford S, McConnell DS, Randolph JF Jr, Gold EB, Wilkin MK, Lasley B. Selected diet and lifestyle factors are associated with estrogen metabolites in a multiracial/ethnic population of women. J Nutr. 2006; 136:1588-95. [PubMed: 16702326]

33. Horn-Ross PL, Lee M, John EM, Koo J. Sources of phytoestrogen exposure among non-Asian women in California, USA. Cancer Causes Control. 2000; 11:299-302. [PubMed: 10843441]

34. Velentzis LS, Cantwell MM, Cardwell C, Keshtgar MR, Leathem AJ, Woodside JV. Lignans and breast cancer risk in pre- and post-menopausal women: meta-analyses of observational studies. $\mathrm{Br}$ J Cancer. 2009; 100:1492-8. [PubMed: 19337250] 
Table 1

Baseline characteristics according to tea and coffee intake in the Black Women's Health Study, 1995

\begin{tabular}{|c|c|c|c|c|}
\hline \multirow[t]{2}{*}{ Characteristic } & \multicolumn{2}{|c|}{ Tea intake, cups } & \multicolumn{2}{|c|}{ Coffee intake, cups } \\
\hline & Never & $\geq 4 / d$ & Never & $\geq 4 / d$ \\
\hline $\mathrm{N}$ & 11,698 & 1,365 & 27,525 & 1,733 \\
\hline Age, years, mean & 39.2 & 41.4 & 37.4 & 44.5 \\
\hline Age at menarche, years, mean & 12.4 & 12.3 & 12.4 & 12.3 \\
\hline BMI at age $18, \mathrm{~kg} / \mathrm{m}^{2}$, mean & 21.6 & 21.4 & 21.3 & 21.9 \\
\hline BMI, $\mathrm{kg} / \mathrm{m}^{2}$, mean & 28.1 & 27.9 & 27.8 & 28.0 \\
\hline Family history of breast cancer, $\%$ & 6.5 & 6.5 & 6.7 & 7.6 \\
\hline Education $\geq 16$ years, $\%$ & 42.4 & 46.7 & 46.5 & 41.5 \\
\hline \multicolumn{5}{|l|}{ Region, \% } \\
\hline Northeast & 21.0 & 40.2 & 27.4 & 28.1 \\
\hline South & 28.9 & 27.8 & 32.6 & 24.3 \\
\hline Midwest & 28.5 & 17.2 & 22.4 & 24.5 \\
\hline West & 21.5 & 14.7 & 17.4 & 23.1 \\
\hline Nulliparous, $\%$ & 33.9 & 37.4 & 36.9 & 35.4 \\
\hline Age at first birth $\geq 25$ years, $\%^{\dagger}$ & 28.1 & 27.9 & 30.4 & 21.3 \\
\hline Oral contraceptive use $\geq 5$ years, $\%$ & 29.9 & 28.0 & 30.6 & 33.4 \\
\hline Female hormone use $\geq 5$ years, $\%$ & 5.1 & 4.5 & 4.9 & 5.3 \\
\hline Vigorous activity $\geq 5$ hrs/wk, $\%$ & 13.7 & 16.3 & 13.6 & 13.6 \\
\hline Current smoker, $\%$ & 18.3 & 18.2 & 10.9 & 37.4 \\
\hline Alcohol intake $\geq 7$ drinks/wk, $\%$ & 6.6 & 6.0 & 4.1 & 8.7 \\
\hline Energy intake, $\mathrm{kcal} / \mathrm{d}$, mean & 1,502 & 2,004 & 1,566 & 1,911 \\
\hline Coffee, cups/wk, mean & 4.8 & 7.3 & - & - \\
\hline Tea, cups/wk, mean & - & - & 4.6 & 7.9 \\
\hline Caffeine, $\mathrm{mg} / \mathrm{d}$, mean & 130 & 403 & 51 & 839 \\
\hline Prudent diet pattern, top quintile, $\%$ & 16.8 & 34.3 & 21.5 & 20.6 \\
\hline Western diet pattern, top quintile, $\%$ & 22.6 & 24.2 & 19.2 & 22.5 \\
\hline
\end{tabular}

All characteristics, with the exception of age, are standardized to the age distribution of the cohort at baseline.

${ }^{\dagger}$ Parous women only 
Table 2

Tea, coffee, and caffeine intake in relation to risk of breast cancer in the Black Women's Health Study, 19952007

\begin{tabular}{|c|c|c|c|c|}
\hline & Cases & Person-years & $\operatorname{IRR}(95 \% \mathrm{CI})^{1}$ & $\operatorname{IRR}(95 \% \mathrm{CI})^{2}$ \\
\hline \multicolumn{5}{|l|}{ Tea, ${ }^{3}$ cups } \\
\hline Never, $<1 /$ mo & 241 & 108,285 & 1.00 (Ref.) & 1.00 (Ref.) \\
\hline$<1 / \mathrm{d}$ & 789 & 351,313 & $1.05(0.91-1.22)$ & $1.04(0.90-1.21)$ \\
\hline $1 / \mathrm{d}$ & 129 & 52,431 & $1.09(0.88-1.35)$ & $1.07(0.86-1.33)$ \\
\hline $2-3 / d$ & 76 & 32,153 & $1.02(0.79-1.33)$ & $1.02(0.78-1.32)$ \\
\hline$\geq 4 / \mathrm{d}$ & 33 & 11,670 & $1.14(0.79-1.65)$ & $1.13(0.78-1.63)$ \\
\hline$P$ for trend & & & 0.64 & 0.67 \\
\hline \multicolumn{5}{|l|}{ Coffee, ${ }^{3}$ cups } \\
\hline Never, $<1 /$ mo & 592 & 274,907 & 1.00 (Ref.) & 1.00 (Ref.) \\
\hline$<1 / \mathrm{d}$ & 357 & 160,676 & $0.97(0.85-1.11)$ & $0.98(0.85-1.12)$ \\
\hline $1 / \mathrm{d}$ & 148 & 59,121 & $0.90(0.75-1.08)$ & $0.91(0.76-1.09)$ \\
\hline $2-3 / d$ & 122 & 45,631 & $0.93(0.77-1.13)$ & $0.94(0.77-1.15)$ \\
\hline$\geq 4 / \mathrm{d}$ & 49 & 15,518 & $1.01(0.75-1.35)$ & $1.03(0.77-1.39)$ \\
\hline$P$ for trend & & & 0.76 & 0.90 \\
\hline \multicolumn{5}{|c|}{ Decaffeinated coffee, ${ }^{3}$ cups } \\
\hline Never, $<1 /$ mo & 827 & 393,352 & 1.00 (Ref.) & 1.00 (Ref.) \\
\hline$<1 / \mathrm{d}$ & 317 & 124,463 & $0.98(0.86-1.12)$ & $0.96(0.84-1.09)$ \\
\hline $1 / \mathrm{d}$ & 76 & 21,923 & $1.07(0.84-1.36)$ & $1.05(0.83-1.33)$ \\
\hline$\geq 2 / \mathrm{d}$ & 48 & 16,114 & $0.84(0.63-1.13)$ & $0.82(0.61-1.11)$ \\
\hline$P$ for trend & & & 0.42 & 0.33 \\
\hline \multicolumn{5}{|l|}{ Caffeine, $\mathrm{mg} / \mathrm{d}$} \\
\hline$<16$ & 228 & 111,183 & 1.00 (Ref.) & 1.00 (Ref.) \\
\hline $16-42$ & 232 & 111,182 & $1.06(0.88-1.27)$ & $1.07(0.89-1.28)$ \\
\hline $43-92$ & 238 & 111,177 & $1.03(0.86-1.24)$ & $1.04(0.87-1.25)$ \\
\hline 93-208 & 265 & 111,165 & $1.02(0.86-1.22)$ & $1.03(0.86-1.24)$ \\
\hline$\geq 209$ & 305 & 111,145 & $1.01(0.85-1.21)$ & $1.04(0.87-1.24)$ \\
\hline$P$ for trend & & & 0.87 & 0.93 \\
\hline \multicolumn{5}{|c|}{ Adjusted for age and energy intake } \\
\hline
\end{tabular}


Table 3

Tea, coffee, and caffeine intake in relation to risk of breast cancer, according to menopausal status, in the Black Women's Health Study, 1995-2007

\begin{tabular}{|c|c|c|c|c|}
\hline & \multicolumn{2}{|c|}{ Premenopausal } & \multicolumn{2}{|c|}{ Postmenopausal } \\
\hline & Cases & $\operatorname{IRR}(95 \% \mathrm{CI})^{1}$ & Cases & $\operatorname{IRR}(95 \% \mathrm{CI})^{1}$ \\
\hline \multicolumn{5}{|l|}{ Tea, ${ }^{2}$ cups } \\
\hline Never, $<1 /$ mo & 107 & 1.00 (Ref.) & 112 & 1.00 (Ref.) \\
\hline$<1 / \mathrm{d}$ & 367 & $1.02(0.82-1.28)$ & 339 & $1.03(0.82-1.28)$ \\
\hline $1 / \mathrm{d}$ & 48 & $0.91(0.64-1.28)$ & 59 & $1.05(0.76-1.45)$ \\
\hline $2-3 / d$ & 29 & $0.88(0.58-1.33)$ & 40 & $1.14(0.79-1.64)$ \\
\hline$\geq 4 / \mathrm{d}$ & 11 & $0.90(0.48-1.69)$ & 20 & $1.44(0.89-2.34)$ \\
\hline$P$ for trend & & 0.43 & & 0.12 \\
\hline \multicolumn{5}{|l|}{ Coffee, ${ }^{2}$ cups } \\
\hline Never, $<1 /$ mo & 281 & 1.00 (Ref.) & 251 & 1.00 (Ref.) \\
\hline$<1 / \mathrm{d}$ & 155 & $0.91(0.75-1.12)$ & 164 & $1.06(0.86-1.29)$ \\
\hline $1 / \mathrm{d}$ & 57 & $0.87(0.65-1.17)$ & 74 & $0.94(0.72-1.23)$ \\
\hline $2-3 / d$ & 49 & $1.00(0.73-1.37)$ & 58 & $0.89(0.66-1.20)$ \\
\hline$\geq 4 / \mathrm{d}$ & 20 & $1.33(0.83-2.11)$ & 23 & $0.85(0.55-1.32)$ \\
\hline$P$ for trend & & 0.31 & & 0.28 \\
\hline \multicolumn{5}{|c|}{ Decaffeinated coffee,$^{2}$ cups } \\
\hline Never, $<1 /$ mo & 405 & 1.00 (Ref.) & 326 & 1.00 (Ref.) \\
\hline$<1 / \mathrm{d}$ & 115 & $0.90(0.72-1.11)$ & 173 & $1.07(0.88-1.30)$ \\
\hline $1 / \mathrm{d}$ & 29 & $1.54(1.05-2.25)$ & 37 & $0.84(0.59-1.19)$ \\
\hline$\geq 2 / \mathrm{d}$ & 13 & $0.99(0.56-1.72)$ & 34 & $0.93(0.65-1.33)$ \\
\hline$P$ for trend & & 0.41 & & 0.42 \\
\hline \multicolumn{5}{|l|}{ Caffeine, $\mathrm{mg} / \mathrm{d}$} \\
\hline$<16$ & 115 & 1.00 (Ref.) & 96 & 1.00 (Ref.) \\
\hline $16-42$ & 110 & $0.96(0.74-1.25)$ & 97 & $1.10(0.83-1.47)$ \\
\hline $43-92$ & 114 & $0.98(0.76-1.27)$ & 98 & $1.05(0.79-1.40)$ \\
\hline 93-208 & 111 & $0.93(0.72-1.21)$ & 125 & $1.08(0.82-1.41)$ \\
\hline$\geq 209$ & 112 & $0.97(0.74-1.26)$ & 154 & $1.03(0.79-1.34)$ \\
\hline$P$ for trend & & 0.86 & & 0.88 \\
\hline
\end{tabular}

${ }^{1}$ Adjusted for age, energy intake, age at menarche, BMI at age 18 , family history of breast cancer, education, geographic region, parity, age at first birth, oral contraceptive use, age at menopause, female hormone use, vigorous activity, smoking status, and alcohol intake

2 Tea, coffee, and decaffeinated coffee mutually adjusted for each other 


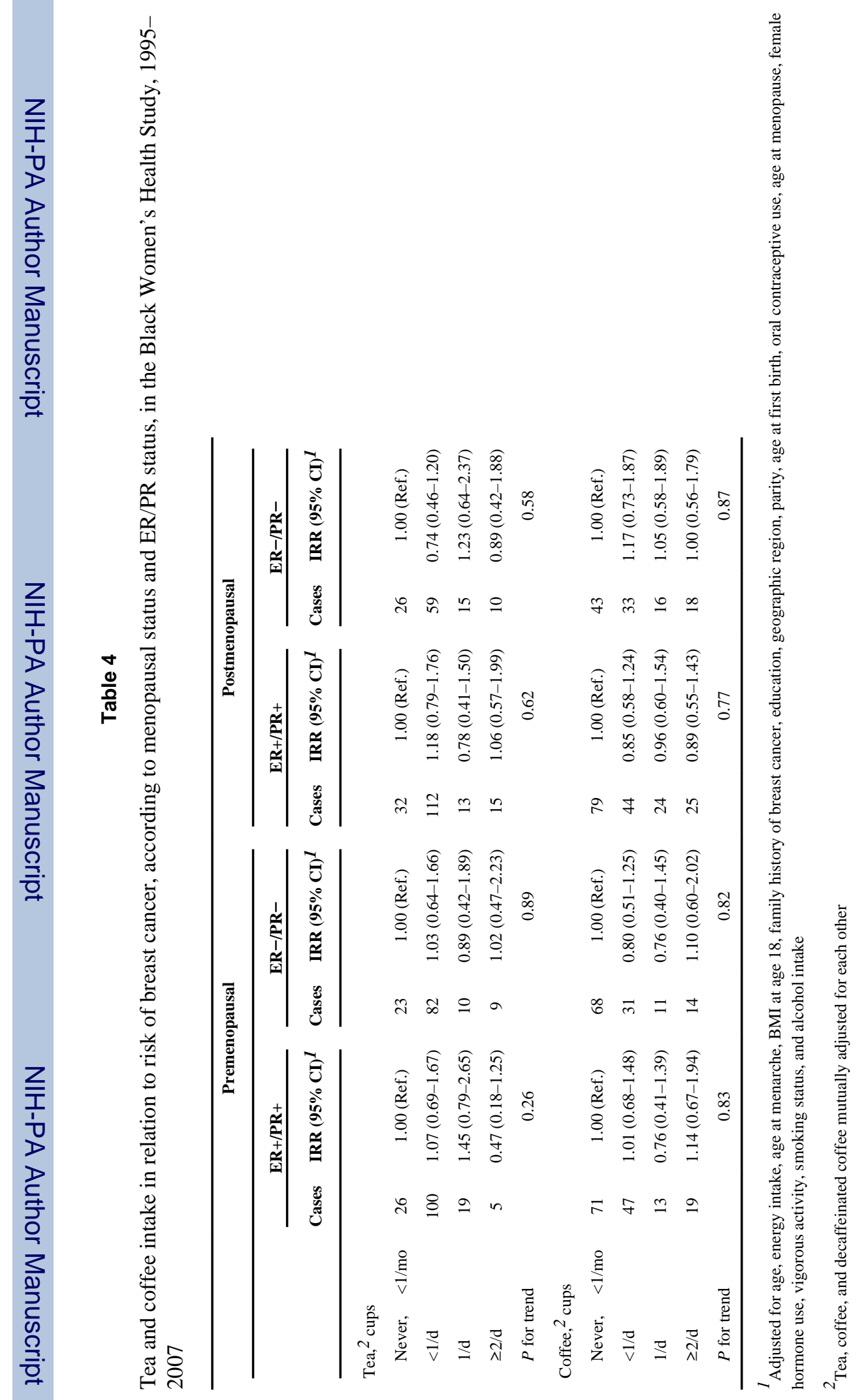

